\title{
Increased Mechanical Properties of Carbon Nanofiber Mats for Possible Medical Applications
}

\author{
Marah Trabelsi ${ }^{1,2}$, Al Mamun ${ }^{1}$, Michaela Klöcker ${ }^{1}$, Lilia Sabantina ${ }^{1}$, Christina Großerhode ${ }^{1}$, \\ Tomasz Blachowicz ${ }^{3}$ and Andrea Ehrmann 1,*(D) \\ 1 Faculty of Engineering and Mathematics, Bielefeld University of Applied Sciences, ITES, 33619 Bielefeld, \\ Germany; marah.trabelsi@enis.tn (M.T.); al.mamun@fh-bielefeld.de (A.M.); \\ michaela.kloecker@fh-bielefeld.de (M.K.); lilia.sabantina@fh-bielefeld.de (L.S.); \\ christina.grosserhode@fh-bielefeld.de (C.G.) \\ 2 Ecole Nationale d'Ingénieurs de Sfax, Sfax 3038, Tunisia \\ 3 Institute of Physics-Center for Science and Education, Silesian University of Technology, 44-100 Gliwice, \\ Poland; tomasz.blachowicz@polsl.pl \\ * Correspondence: andrea.ehrmann@fh-bielefeld.de
}

Received: 30 September 2019; Accepted: 13 November 2019; Published: 17 November 2019

\begin{abstract}
Carbon fibers belong to the materials of high interest in medical application due to their good mechanical properties and because they are chemically inert at room temperature. Carbon nanofiber mats, which can be produced by electrospinning diverse precursor polymers, followed by thermal stabilization and carbonization, are under investigation as possible substrates for cell growth, especially for possible 3D cell growth applications in tissue engineering. However, such carbon nanofiber mats may be too brittle to serve as a reliable substrate. Here we report on a simple method of creating highly robust carbon nanofiber mats by using electrospun polyacrylonitrile/ZnO nanofiber mats as substrates. We show that the ZnO-blended polyacrylonitrile (PAN) nanofiber mats have significantly increased fiber diameters, resulting in enhanced mechanical properties and thus supporting tissue engineering applications.
\end{abstract}

Keywords: electrospinning; nanofiber mat; ZnO; polyacrylonitrile (PAN); brittleness

\section{Introduction}

Electrospinning allows for the creation of thin fibers in the diameter range between some ten and several hundred micrometers from diverse polymers or polymer blends [1]. Such nanofibers can be used, for example, for air filtration, [2-4], water filtration [5-7], batteries [8] or biomedical applications [9-11].

One of the typical materials often used as a precursor of carbon nanofibers is polyacrylonitrile (PAN) $[12,13]$. This polymer has the additional advantage of being spinnable from the low-toxic solvent dimethyl sulfoxide (DMSO) [14].

Such PAN nanofiber mats can afterwards be stabilized, typically in air, to enable a chemical cyclization process, including the oxidation, aromatization, dehydrogenation, crosslinking and formation of a thermally stable aromatic ladder polymer [15-18]. This first thermal treatment can be performed, for example, by heating the nanofiber mat to temperatures around $260^{\circ} \mathrm{C}-290^{\circ} \mathrm{C}$, approached with heating rates between $0.5 \mathrm{~K} / \mathrm{min}$ and $5 \mathrm{~K} / \mathrm{min}$ [19-21], but can also be performed with higher temperatures [22] or split into two different stages [23].

A problem which is scarcely discussed in the scientific literature, however, is the dimensional change of the nanofiber mats during stabilization and carbonization, typically linked to a morphological change of the nanofibers themselves, which become thicker, shorter and wavier due to the relaxation of 
the frozen strain, resulting from the severe stretching during electrospinning [21]. Different strategies are discussed in the literature to avoid this morphological change, which is also connected to a loss of the mechanical stability of the carbon nanofiber mats. Typically, bundles of nanofibers are stretched during stabilization [24-26] and partly even during carbonization [27]. However, this process cannot be transferred to nanofiber mats created by needleless electrospinning. The latter can be fixed instead, which often leads to shrinking in one direction, if only two sides are fixed, or breaking of the mat even at low heating rates [28-30]. To enable the fixing of the nanofiber mats, not only along the borders, but over the whole plane, the nanofiber mats can be electrospun on aluminum foils as substrates and stabilized on these substrates, from which they are separated afterwards [31]. However, this method is better suited for the batch production of nanofiber mats than for continuous production, which is typically performed on a textile substrate delivered to the spinning chamber by a roll-to-roll process.

Here we report on another method to unambiguously retain the original nanofiber morphology during carbonization and, most importantly, to create soft, bendable carbon nanofiber mats. By adding $\mathrm{ZnO}$ to the PAN solution, significantly thicker nanofibers are created during electrospinning, resulting in an unchanged morphology during carbonization. $\mathrm{ZnO}$ can be used as a gas sensor [32] or for photocatalytic degradation [33]. It is known to be non-cytotoxic, but shows high antibacterial activity against Staphylococcus aureus and Escherichia. coli [34], making such fibers well suited for medical applications such as wound dressings [35] or as a substrate for cell growth in tissue engineering [36].

\section{Materials and Methods}

The needleless electrospinning machine "Nanospider Lab" (Elmarco Ltd., Liberec, Czech Republic) was used to prepare nanofiber mats. We applied the following spinning parameters: high voltage $80 \mathrm{kV}$, nozzle diameter $0.9 \mathrm{~mm}$, carriage speed $100 \mathrm{~mm} / \mathrm{s}$, distance between bottom electrode and substrate $240 \mathrm{~mm}$, distance between ground electrode and substrate $50 \mathrm{~mm}$, temperature in the spinning chamber $24{ }^{\circ} \mathrm{C}$ and relative humidity $33 \%$. The spinning duration was $20 \mathrm{~min}$ (areal weight $4.7 \mathrm{~g} / \mathrm{m}^{2}$ ).

The spinning solution used here was prepared by dissolving $15 \mathrm{wt} . \%$ PAN and $5 \mathrm{wt} . \% \mathrm{ZnO}$ (nano powder $<100 \mathrm{~nm}$ particle size, Sigma-Aldrich, Germany) in DMSO (min. 99.9\%, purchased from S3 Chemicals, Bad Oeynhausen, Germany). For comparison, pure PAN nanofiber mats were electrospun from $16 \mathrm{wt} . \%$ PAN dissolved in DMSO. The slightly higher amount of PAN was necessary to reach a sufficient viscosity of the polymer solution and thus to avoid the formation of beads along the fibers. Especially for dyeing tests, we used a woven cotton fabric with thickness $0.19 \mathrm{~mm}$ and areal weight $84.49 \mathrm{~g} / \mathrm{m}^{2}$.

A muffle furnace B150 (Nabertherm, Lilienthal, Germany) was used to stabilize the nanofiber mats, using a heating rate of $1 \mathrm{~K} / \mathrm{min}$ to reach a maximum temperature of $280^{\circ} \mathrm{C}$, followed by isothermal treatment for $1 \mathrm{~h}$.

For carbonization, a furnace CTF 12/TZF 12 (Carbolite Gero, Neuhausen, Germany) was used, in which a temperature of $500{ }^{\circ} \mathrm{C}$ was reached with a heating rate of $10 \mathrm{~K} / \mathrm{min}$, applying a nitrogen flow of $150 \mathrm{~mL} / \mathrm{min}$ (standard temperature and pressure, STP), again followed by isothermal treatment for $1 \mathrm{~h}$.

For dyeing tests, a forest fruit tea solution (Mayfair, Wilken Tee GmbH, Fulda, Germany) was applied. For this, $2.5 \mathrm{~g}$ tea was mixed with $30 \mathrm{~g}$ distilled water, and the tea was extracted for $30 \mathrm{~min}$. Samples were dyed for $30 \mathrm{~min}$ in a solution that contained anthocyanins as dye molecules and were dried at room temperature.

Investigations of the sample surfaces were performed using a digital microscope VHX-600D (Keyence, Neu-Isenburg, Germany), as well as a scanning electron microscope (SEM) Zeiss 1450VPSE (Oberkochen, Germany) for more detailed examinations. Chemical evaluation was performed by Fourier-transform infrared (FTIR) spectroscopy, using an Excalibur 3100 (Varian, Inc., Palo Alto, CA, USA). Fiber diameters were investigated using ImageJ 1.51j8 (from National Institutes of Health, Bethesda, MD, USA). 


\section{Results and Discussion}

The morphology of the raw electrospun PAN/ZnO nanofiber mats is depicted in Figure 1, showing SEM images with identical magnification, taken at different sample positions. Generally, the fibers are much thicker than common PAN nanofibers, which have average diameters of $160 \pm 40 \mathrm{~nm}$, electrospun under identical conditions [31], or the PAN nanofibers created here, resulting in an average diameter of $140 \pm 40 \mathrm{~nm}$, as calculated from SEM images. For the PAN/ZnO nanofibers under investigation here, the average diameter is $450 \pm 120 \mathrm{~nm}$, i.e., approximately three times the common PAN nanofiber diameter.

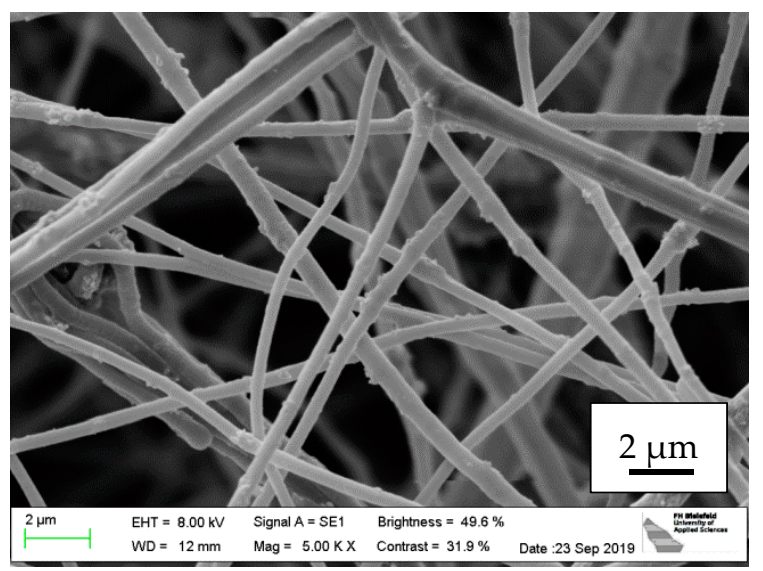

(a)

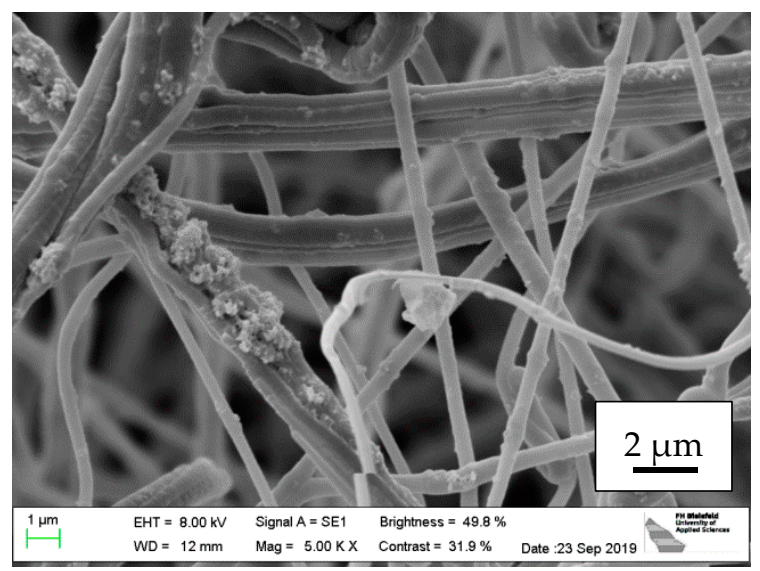

(b)

Figure 1. Scanning electron microscopy SEM images of an electrospun polyacrylonitrile (PAN)/ZnO nanofiber mat, taken at different sample positions.

While in most applications, the nanofibers used have a very high surface-to-volume ratio, here the increase of the nanofiber diameter is not critical. Earlier investigations of the growth of Chinese hamster ovary $(\mathrm{CHO})$ cells on different nanofiber mats revealed that growing on pure PAN nanofiber mats with their typical thin fiber diameters was impossible, while the cells grew well on PAN/gelatin nanofiber mats [36] with average fiber diameters of $490 \pm 130 \mathrm{~nm}$ [37].

On the other hand, some of the fibers already show agglomerations of $\mathrm{ZnO}$ on the surface (Figure 1b). This indicates that the $\mathrm{ZnO}: \mathrm{PAN}$ ratio chosen here, which is uncritical for electrospinning, may be too high and could be reduced in further experiments, depending on the desired application. It should be mentioned that this finding is similar to earlier investigations of $\mathrm{PAN} / \mathrm{TiO}_{2}$ nanofiber mats, which did not show increased fiber diameters, but also partly exhibited $\mathrm{TiO}_{2}$ agglomerations along the fibers for a broad range of $\mathrm{TiO}_{2}$ contents between $2.2 \%$ and $10.2 \%$ [38]. Former tests to reduce the $\mathrm{TiO}_{2}$ agglomerations by longer stirring time, additional ultrasonic dispersion, reduced time between stirring and electrospinning, etc. indicated a general possibility to obtain a more homogeneous distribution of the $\mathrm{TiO}_{2}$ and thus to reduce these agglomerations. Depending on the desired application-whether applications fixed along the fibers are undesired or even advantageous-similar experiments in combination with a variation of the $\mathrm{ZnO}$ content are necessary.

Next, it was tested whether the $\mathrm{ZnO}$ is freely available and could thus support the antibacterial activity of such samples [34]. Former investigations of $\mathrm{PAN} / \mathrm{TiO}_{2}$ nanofiber mats revealed very slow methylene blue degradation, indicating that only a small amount of $\mathrm{TiO}_{2}$ is in contact with the environment [39]. Here, an easier method was used to investigate whether a significant amount of $\mathrm{ZnO}$ is in contact with the environment. $\mathrm{ZnO}$ belongs to the semiconductors used in dye-sensitized solar cells, typically showing a clearly visible bathochromic shift of the color of diverse dyes adsorbed on the material [40-43].

Figure 2 shows microscopic images of different raw and dyed fabrics. Figure 2a depicts a dyed cotton fabric, showing the typical color of the tea solution. The original PAN/ZnO nanofiber mat 
(Figure 2b) shows white fibers. After dyeing such a nanofiber mat, drying and rinsing it with water, the nanofiber mat again looks white (Figure 2c). Obviously, not even the reddish color of the cotton fabric is reached. This is in strong contrast to dyeing a PAN/ZnO nanofiber mat that was previously dip-coated into an aqueous $\mathrm{ZnO}$ solution, showing the typical lilac color after the bathochromic shift due to the binding of the anthocyanins to the $\mathrm{ZnO}$ (Figure 2d), as it is also well-known from $\mathrm{TiO}_{2}$ dyed with anthocyanins [44]. Apparently, no visible amount of $\mathrm{ZnO}$ could be dyed.

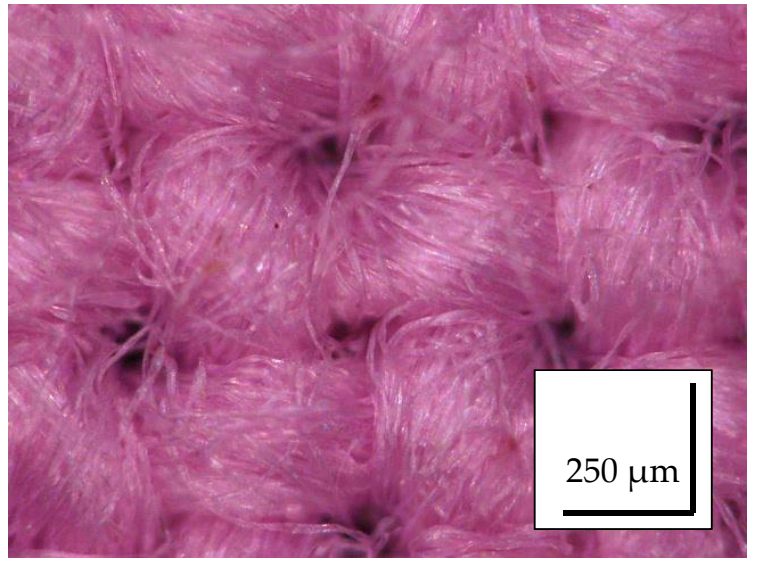

(a)

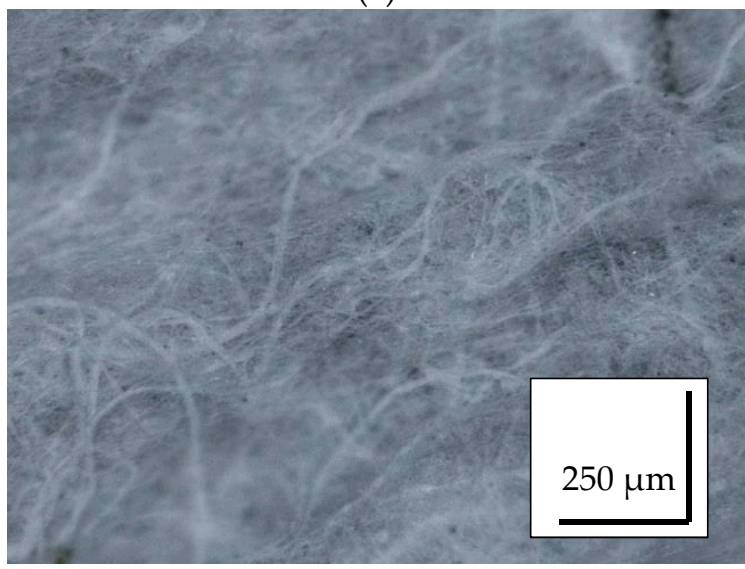

(c)

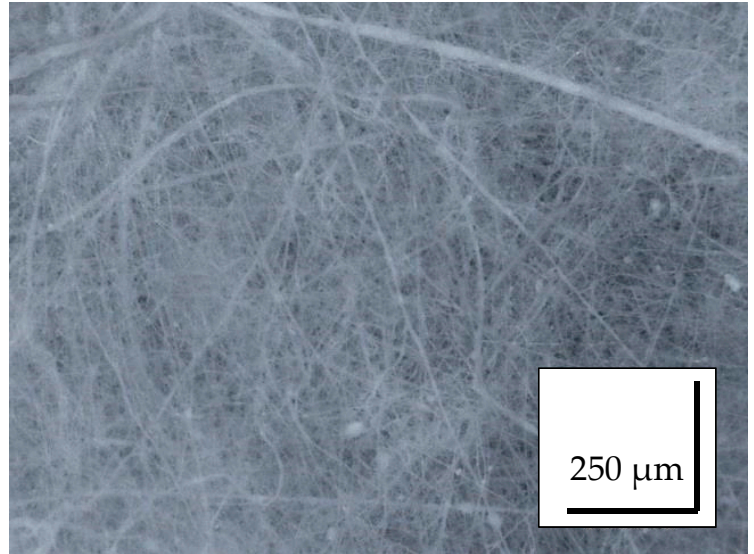

(b)

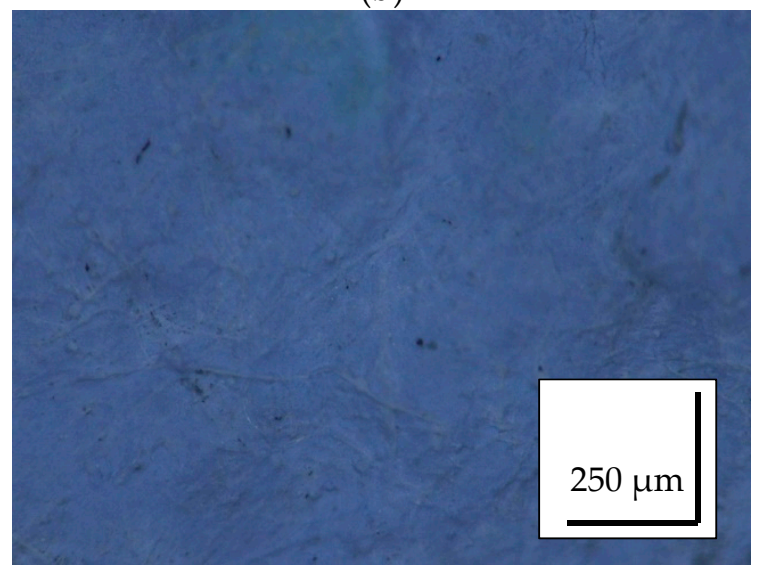

(d)

Figure 2. Microscopic images of (a) a cotton fabric dyed with anthocyanins; (b) a PAN/ZnO nanofiber mat; (c) a PAN/ZnO nanofiber mat dyed with anthocyanins; (d) a PAN/ZnO nanofiber mat dip-coated in $\mathrm{ZnO}$ and dyed with anthocyanins.

Depending on the desired application, it may be supportive to have a relatively inert fabric without the antibacterial activity of $\mathrm{ZnO}$. However, for many applications, the antibacterial—or photocatalytic or other-properties of $\mathrm{ZnO}$ may be desired. Thus, it was tested whether $\mathrm{ZnO}$ nanoparticles could be coated on the PAN/ZnO fabric afterwards. While a previous experiment revealed the strong adhesion of $\mathrm{TiO}_{2}$ nanoparticles in PAN nanofiber mats [44], the modified morphology of the PAN/ZnO nanofiber mat may also change the adhesion of nanoparticles coated on the fibers.

Unexpectedly, PAN/ZnO nanofibers enabled the even stronger adhesion of additional $\mathrm{ZnO}$ nanoparticles than pure PAN nanofiber mats. Figure 3 depicts both nanofiber mats, dip-coated in an aqueous $\mathrm{ZnO}$ solution, dried at ambient temperature and afterwards rinsed with water. It is clearly visible that more $\mathrm{ZnO}$ nanoparticles adhered to the PAN/ZnO nanofiber mat than to the PAN substrate. This is in contrast to coating PAN nanofiber mats with $\mathrm{TiO}_{2}$, resulting in nano-composites that could even be applied as photo-electrodes in dye-sensitized solar cells [44]. 


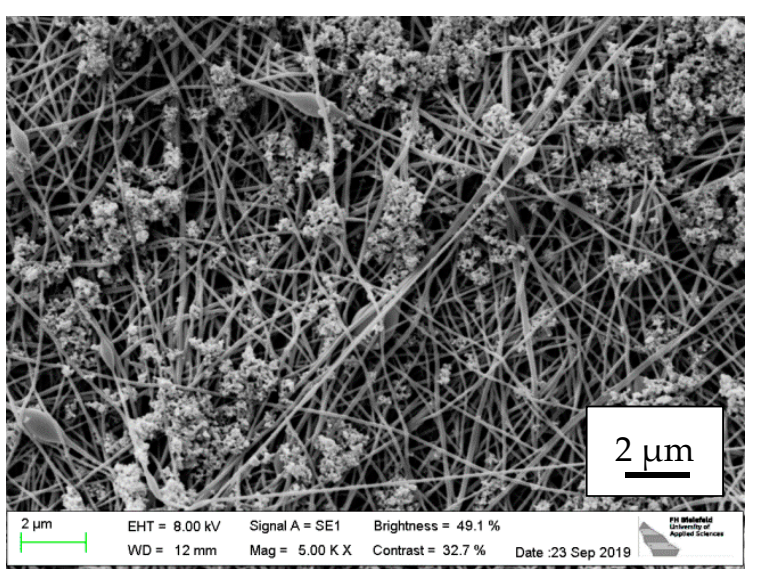

(a)

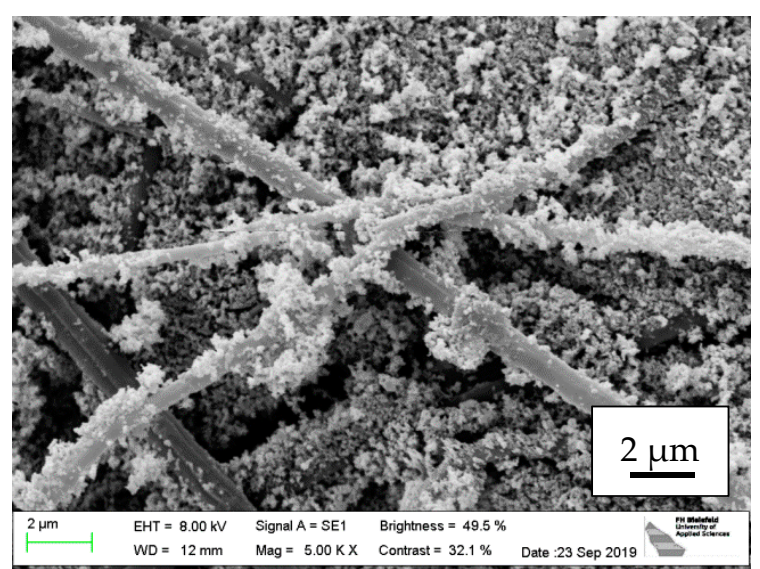

(b)

Figure 3. SEM images of ZnO nanoparticles, applied by dip-coating on (a) a PAN nanofiber mat; (b) a $\mathrm{PAN} / \mathrm{ZnO}$ nanofiber mat, after rinsing the substrates with water.

While the previous investigations concentrated on raw PAN/ZnO nanofiber mats, the main aim was the stabilization and carbonization of the electrospun samples. Figure 4 thus shows microscopic images of stabilized and carbonized PAN and PAN/ZnO nanofiber mats, respectively.

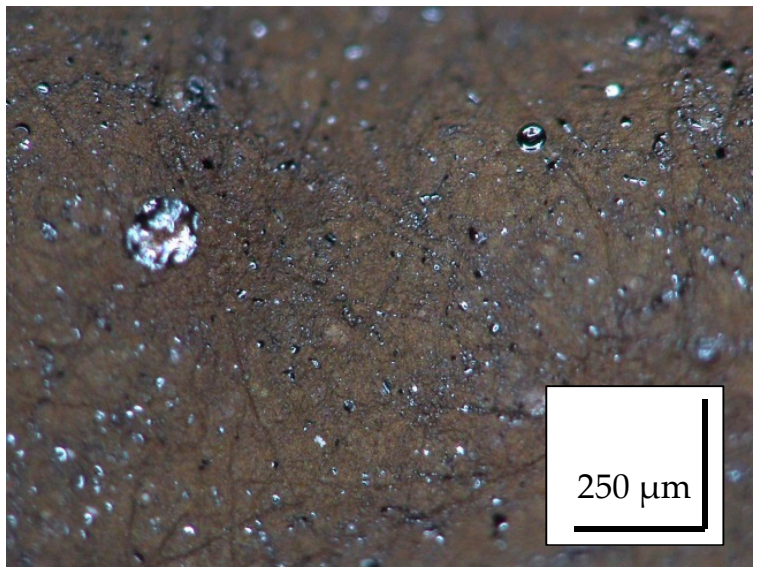

(a)

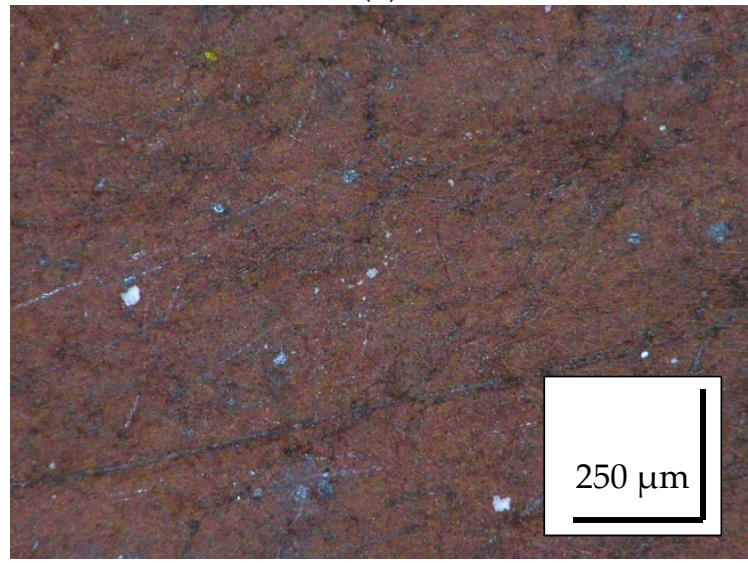

(c)

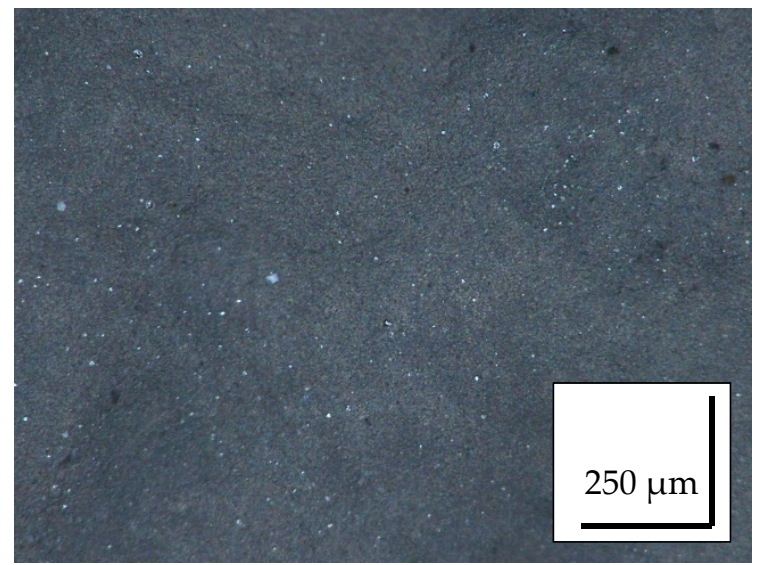

(b)

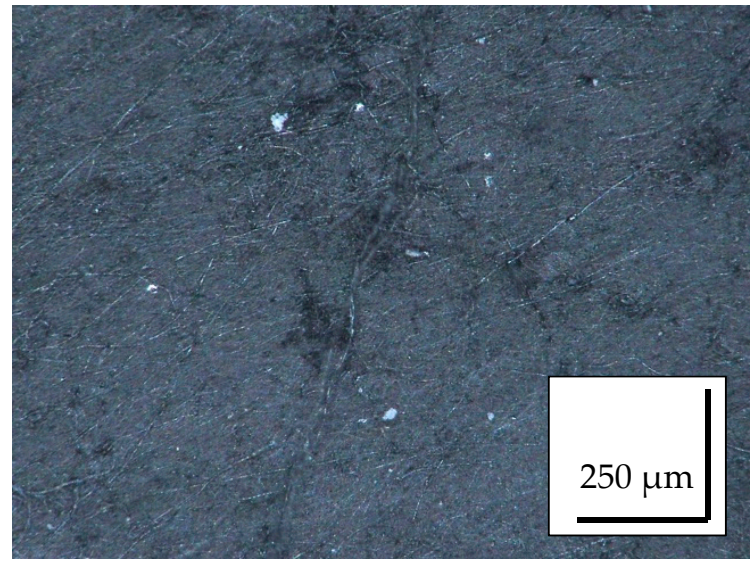

(d)

Figure 4. Microscopic images of (a) a stabilized PAN nanofiber mat; (b) a carbonized PAN nanofiber mat; (c) a stabilized PAN/ZnO nanofiber mat; (d) a carbonized PAN/ZnO nanofiber mat.

While the PAN fibers are too fine to be visible in these microscopic images, the stabilized and carbonized PAN/ZnO samples clearly show a fibrous structure. Carbonization at identical temperatures 
results in the more or less identical dark-grey color of the carbonized samples, while the brown colors of the stabilized samples differ slightly. The reddish brown of the stabilized PAN/ZnO nanofiber mat is similar to the color of the stabilized PAN/gelatin nanofibers, which has a similar diameter [37], suggesting that this color change may be attributed to diffraction at the nanofibers.

More importantly, the carbonized PAN/ZnO nanofiber mats are highly bendable. Figure 5 depicts carbonized nanofiber mats from pure electrospun PAN and PAN/ZnO nanofiber mats as precursors, respectively. The carbonized PAN nanofiber mat, stabilized and carbonized without fixation, breaks directly when grasped with the tweezers. Oppositely, the carbonized PAN/ZnO nanofiber mat, stabilized and carbonized under identical conditions, is bendable without any tendency to break, making this material more easily usable in applications such as 3D substrates for tissue engineering, where they are not used in a plane shape.

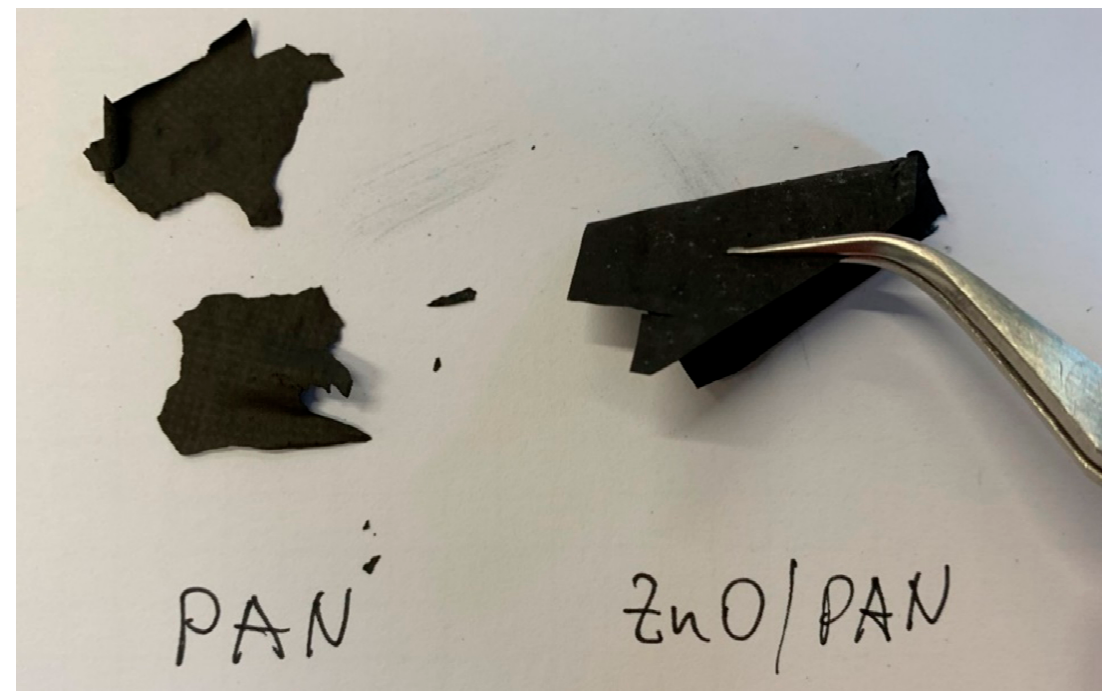

Figure 5. Bending a carbonized PAN nanofiber mat (stabilized without fixation) only slightly results in brittle failure (left side), while bending carbonized PAN/ZnO nanofiber mats (stabilized without fixation) is possible with a narrow bending radius (right side).

Finally, some other properties of the PAN/ZnO nanofiber mats are given. From the physical point of view, it is interesting that the carbon nanofiber mats produced from this precursor are not conductive (i.e., the sheet resistance is higher than $20 \mathrm{M} \Omega$ ), opposite to PAN nanofiber mats carbonized under identical conditions [44].

For diverse applications, the carbon yield is an important factor, i.e., the ratio of the mass retained after carbonization to the mass of the original nanofiber mat. Typical values of the stabilization yield for a PAN nanofiber mat after stabilization with the process parameters applied here are in the range of $72 \%$, the corresponding carbonization yield is approx. $29 \%$, resulting in an overall mass yield of $21 \%$ [30].

For the PAN/ZnO nanofiber mats under investigation here, the stabilization yield is approx. $74 \%$, while the carbonization yield is approx. $76 \%$, resulting in an overall mass yield of $56 \%$. While this seems to be a very promising result at first glance, it must be taken into account, nevertheless, that $\frac{1}{4}$ of the dry mass of the raw nanofiber mat consists of $\mathrm{ZnO}$, which is thermally stable up to nearly $2000{ }^{\circ} \mathrm{C}$ and stays thus unaltered during carbonization at $500{ }^{\circ} \mathrm{C}$. This reduces the overall carbon gain to $(100 \%$ $-25 \%) /(56 \%-25 \%)=41 \%$. This value is still approximately twice as high as the overall mass yield from a pure PAN nanofiber mat, indicating that future research on this topic is necessary to investigate the specific chemical or physical properties of the carbon/ZnO nanofiber mats that are necessary for different applications. Since this finding is unexpected, FTIR investigations were used to evaluate the chemical properties of the carbon/ZnO nanofiber mats. 
Results for PAN/ZnO nanofiber mats in a raw state, after stabilization and carbonization, are depicted in Figure 6a. A ZnO absorption peak could be expected near $430 \mathrm{~cm}^{-1}$ [45], which cannot be achieved in the FTIR instrument used for this investigation. Annealing can be expected to reduce possible impurities in the $\mathrm{ZnO}$ so that no additional peaks should be visible in the spectra of the stabilized and the carbonized nanofiber mats [46].

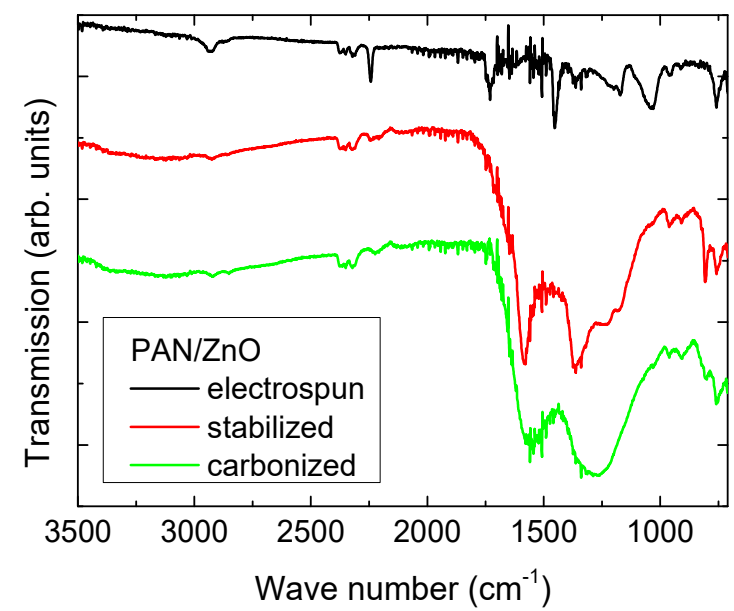

(a)

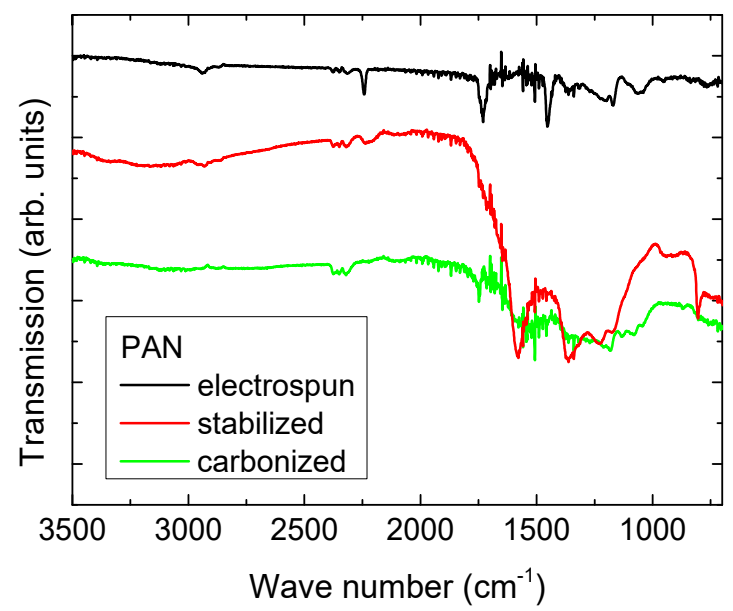

(b)

Figure 6. FTIR graphs of electrospun, stabilized and carbonized nanofiber mats from (a) PAN/ZnO;

(b) PAN.

The spectra for raw and stabilized PAN/ZnO nanofiber mats indeed show the peaks expected for raw and stabilized PAN, as discussed in detail in [11,20]. The spectrum of the carbonized sample, however, shows clear residues of the stabilized material, indicating that carbonization is not completed here. For a better comparison, Figure $6 \mathrm{~b}$ shows the corresponding spectra of a PAN nanofiber mat after electrospinning, stabilization and carbonization. While the first two spectra are qualitatively identical with those of $\mathrm{PAN} / \mathrm{ZnO}$, the latter shows clearly reduced features, underlining nearly complete carbonization.

This effect may be based on the increased nanofiber diameter, impeding sufficient heat supply to the fiber core. In other thicker nanofibers, like PAN/gelatin or PAN/poly(vinylidene fluoride), this problem may not occur since the blend partners are typically dissolved at temperatures below $500{ }^{\circ} \mathrm{C}[36,47]$, while $\mathrm{PAN} / \mathrm{TiO}_{2}$ nanofibers do not show an increased fiber diameter and thus behave similar to pure PAN fibers during carbonization [38]. The same effect of incomplete carbonization under identical conditions was already found for the carbonization of pure PAN nanofibers electrospun with a low voltage of $50 \mathrm{kV}$, resulting in thicker fibers, where no chemical difference to the usual PAN nanofibers electrospun with $80 \mathrm{kV}$, as done here, can be expected (to be published). This underlines that optimal carbonization parameters do not only have to be distinguished between nanofibers and microfibers, but also between differently electrospun nanofibers with correspondingly different diameters.

The FTIR graphs clearly show that a deeper investigation of the carbonization process and possibly even an optimization of the stabilization step are necessary to create carbon/ZnO nanofiber mats with good mechanical and reliable chemical properties.

\section{Conclusions}

PAN/ZnO nanofiber mats were prepared by electrospinning, resulting in nanofibers with diameters approximately three times the value of pure PAN nanofibers. While the $\mathrm{ZnO}$ included in the polymer matrix was not in contact with the environment, as shown by a simple dyeing test, additional $\mathrm{ZnO}$ nanoparticles adhered better on these nanofiber mats than on those from pure PAN, enabling the addition of antibacterial or other desired properties of $\mathrm{ZnO}$. 
Stabilization and carbonization with the process parameters typical for PAN nanofiber mats resulted in highly flexible nanofiber mats. FTIR investigations revealed that carbonization was not completed for the PAN/ZnO nanofiber mats, suggesting further investigation and optimization of the carbonization, and possibly also of the stabilization, process is needed to prepare flexible carbon/ZnO nanofiber mats with well-defined chemical properties as 3D substrates in tissue engineering.

Author Contributions: Conceptualization, T.B., L.S. and A.E.; formal analysis, L.S., A.E. and T.B.; investigation, M.T., A.M., M.K., L.S. and C.G.; writing—original draft preparation, A.E.; writing-review and editing, all authors; visualization, A.E.; supervision, A.E. and T.B.

Funding: This project was funded by the Erasmus+ program of the European Union, by the HiF funds of Bielefeld University of Applied Sciences, by the Deutsche Bundesstiftung Umwelt DBU (German Federal Environmental Foundation) and by the Silesian University of Technology (SUT) Rector Grant 14/990/RGJ18/0099. This article was funded by the Open Access Publication Fund of Bielefeld University of Applied Sciences and the Deutsche Forschungsgemeinschaft (DFG, German Research Foundation)—414001623.

Conflicts of Interest: The authors declare no conflict of interest. The funders had no role in the design of the study; in the collection, analyses, or interpretation of data; in the writing of the manuscript; or in the decision to publish the results.

\section{References}

1. Greiner, A.; Wendorff, J.H. Electrospinning: A fascinating method for the preparation of ultrathin fibers. Angew. Chem. Int. Ed. 2007, 46, 5670-5703. [CrossRef] [PubMed]

2. Lv, D.; Wang, R.X.; Tang, G.S.; Mou, Z.P.; Lei, J.D.; Ha, J.Q.; de Smedt, S.; Xiong, R.H. Correction to Ecofriendly Electrospun Membranes Loaded with Visible-Light-Responding Nanoparticles for Multifunctional Usages: Highly Efficient Air Filtration, Dye Scavenging, and Bactericidal Activity. ACS Appl. Mater. Interfaces 2019, 11, 12880-12889. [CrossRef] [PubMed]

3. Zhu, M.M.; Han, J.Q.; Wang, F.; Shao, W.; Xiong, R.H.; Zhang, Q.L.; Pan, H.; Yang, Y.; Samal, S.K.; Zhang, F.; et al. Electrospun Nanofibers Membranes for Effective Air Filtration. Macromol. Mater. Eng. $2017,302$. [CrossRef]

4. Lv, D.; Zhu, M.M.; Jiang, Z.C.; Jiang, S.H.; Zhang, Q.L.; Xiong, R.H.; Huang, C.B. Green Electrospun Nanofibers and Their Application in Air Filtration. Macromol. Mater. Eng. 2018, 303. [CrossRef]

5. Qin, X.-H.; Wang, S.-Y. Electrospun nanofibers from crosslinked poly(vinyl alcohol) and its filtration efficiency. Appl. Polym. Sci. 2008, 109, 951-956. [CrossRef]

6. Roche, R.; Yalcinkaya, F. Incorporation of PVDF nanofibre multilayers into functional structure for filtration applications. Nanomaterials 2018, 8,771. [CrossRef]

7. Roche, R.; Yalcinkaya, F. Electrospun polyacrylonitrile nanofibrous membranes for point-of-use water and air cleaning. ChemistryOpen 2019, 8, 97-103. [CrossRef]

8. Fu, Q.S.; Lin, G.; Chen, X.D.; Yu, Z.X.; Yang, R.S.; Li, M.T.; Zeng, X.G.; Chen, J. Mechanically Reinforced $\mathrm{PVdF} / \mathrm{PMMA} / \mathrm{SiO}_{2}$ Composite Membrane and Its Electrochemical Properties as a Separator in Lithium-Ion Batteries. Energy Technol. 2018, 6, 144-152. [CrossRef]

9. Gao, S.T.; Tang, G.S.; Hua, D.W.; Xiong, R.H.; Han, J.Q.; Jiang, S.H.; Zhang, Q.L.; Huang, C.B. Stimuli-responsive bio-based polymeric systems and their applications. J. Mater. Chem. B 2019, 7, 709-729. [CrossRef]

10. Sabantina, L.; Kinzel, F.; Hauser, T.; Többer, A.; Klöcker, M.; Döpke, C.; Böttjer, R.; Wehlage, D.; Rattenholl, A.; Ehrmann, A. Comparative study of Pleurotus ostreatus mushroom grown on modified PAN nanofiber mats. Nanomaterials 2019, 9, 475. [CrossRef]

11. Klinkhammer, K.; Seiler, N.; Grafahrend, D.; Gerardo-Nava, j.; Mey, J.; Brook, G.A.; Möller, M.; Dalton, P.D.; Klee, D. Deposition of electrospun fibers on reactive substrates for In Vitro investigations. Tissue Eng. Part C 2009, 15, 77-85. [CrossRef] [PubMed]

12. Rahaman, M.S.A.; Ismail, A.F.; Mustafa, A. A review of heat treatment on polyacrylonitrile fiber. Polym. Degrad. Stab. 2007, 92, 1421-1432. [CrossRef]

13. Sabantina, L.; Mirasol, J.R.; Cordero, T.; Finsterbusch, K.; Ehrmann, A. Investigation of Needleless Electrospun PAN Nanofiber Mats. AIP Conf. Proc. 2018, 1952. [CrossRef] 
14. Grothe, T.; Wehlage, D.; Böhm, T.; Remche, A.; Ehrmann, A. Needleless electrospinning of PAN nanofibre mats. Tekstilec 2017, 60, 290-295. [CrossRef]

15. Chen, J.; Harrison, I. Modification of polyacrylonitrile (PAN) carbon fiber precursor via postspinning plasticization and stretching in dimethyl formamide (DMF). Carbon 2002, 40, 25-45. [CrossRef]

16. Bashir, Z. A critical review of the stabilisation of polyacrylonitrile. Carbon 1991, 29, 1081-1090. [CrossRef]

17. Dalton, S.; Heatley, F.; Budd, P.M. Thermal stabilization of polyacrylonitrile fibres. Polymer 1999, 40, 5531-5543. [CrossRef]

18. Ismar, E.; Sezai Sarac, A. Oxidation of polyacrylonitrile nanofiber webs as a precursor for carbon nanofiber: Aligned and non-aligned nanofibers. Polym. Bull. 2017, 75, 485-499. [CrossRef]

19. Fitzer, E.; Frohs, W.; Heine, M. Optimization of stabilization and carbonization treatment of PAN fibres and structural characterization of the resulting carbon fibres. Carbon 1986, 24, 387-395. [CrossRef]

20. Mólnar, K.; Szolnoki, B.; Toldy, A.; Vas, L.M. Thermochemical stabilization and analysis of continuously electrospun nanofibers. J. Therm. Anal. Calorim. 2014, 117, 1123-1135. [CrossRef]

21. Sabantina, L.; Klöcker, M.; Wortmann, M.; Rodrígues-Mirasol, J.; Cordero, T.; Moritzer, E.; Finsterbusch, K.; Ehrmann, A. Stabilization of PAN nanofiber mats obtained by needleless electrospinning using DMSO as solvent. J. Ind. Text. 2018. [CrossRef]

22. Mathur, R.; Bahl, O.; Mittal, J. A new approach to thermal stabilization of PAN fibres. Carbon 1992, 30, 657-663. [CrossRef]

23. Moon, S.C.; Farris, R.J. Strong electrospun nanometer-diameter polyacrylonitrile carbon fiber yarns. Carbon 2009, 47, 2829-2839. [CrossRef]

24. Wu, S.; Zhang, F.; Yu, Y.H.; Li, P.; Yang, X.P.; Lu, J.G.; Rye, S.K. Preparation of PAN-based carbon nanofibers by hot-stretching. Compos. Interfaces 2008, 15, 671-677. [CrossRef]

25. Xie, Z.; Niu, H.; Lin, T. Continuous polyacrylonitrile nanofiber yarns: Preparation and drydrawing treatment for carbon nanofiber production. RSC Adv. 2015, 5, 15147-15153. [CrossRef]

26. Ma, S.; Liu, J.; Liu, Q.; Liang, J.Y.; Zhao, Y.; Fong, H. Investigation of structural conversion and size effect from stretched bundle of electrospun polyacrylonitrile copolymer nanofibers during oxidative stabilization. Mater. Des. 2016, 95, 387-397. [CrossRef]

27. Ma, S.; Liu, J.; Qu, M.; Wang, X.; Huang, R.; Liang, J. Effects of carbonization tension on the structural and tensile properties of continuous bundles of highly aligned electrospun carbon nanofibers. Mater. Lett. 2016, 183, 369-373. [CrossRef]

28. Wu, M.; Wang, Q.Y.; Li, K.; Wu, Y.Q.; Liu, H.Q. Optimization of stabilization conditions for electrospun polyacrylonitrile nanofibers. Polym. Degrad. Stab. 2012, 97, 1511-1519. [CrossRef]

29. Santos de Oliveira, M.J.; Manzolli Rodrigues, B.V.; Marcuzzo, J.S.; Guerrini, L.M.; Baldan, M.R.; Rezende, M.C. A statistical approach to evaluate the oxidative process of electrospun polyacrylonitrile ultrathin fibers. J. Appl. Polym. Sci. 2017, 134. [CrossRef]

30. Sabantina, L.; Wehlage, D.; Klöcker, M.; Mamun, A.; Grothe, T.; Rodrígues Mirasol, J.; Cordero, T.; Finsterbusch, K.; Ehrmann, A. Stabilization of electrospun PAN/gelatin nanofiber mats for carbonization. J. Nanomater. 2018, 2018. [CrossRef]

31. Sabantina, L.; Ángel Rodríguez-Cano, M.; Klöcker, M.; García-Mateos, F.J.; Ternero-Hidalgo, J.J.; Mamun, A.; Beermann, F.; Schwakenberg, M.; Voigt, A.-L.; Rodríguez-Mirasol, J.; et al. Fixing PAN nanofiber mats during stabilization for carbonization and creating novel metal/carbon composites. Polymers 2018, 10, 735. [CrossRef] [PubMed]

32. Kim, J.H.; Mirzaei, A.; Kim,H.W.; Wu, P.; Kim, S.S. Design of supersensitive and selective ZnO-nanofiber-based sensors for $\mathrm{H} 2$ gas sensing by electron-beam irradiation. Sens. Actuators B Chem. 2019, 293, 210-223. [CrossRef]

33. Yun, S.I.; Kim, S.H.; Kim, D.W.; Kim, Y.A.; Kim, B.H. Facile preperation and capacitive properties of low-cost carbon nanofibers with $\mathrm{ZnO}$ derived lignin and pitch as supercapacitor electrodes. Carbon 2019, 149, 637-645. [CrossRef]

34. Chen, Y.; Lu, W.P.; Guo, Y.C.; Zhu, Y.; Song, Y.P. Electrospun gelatin fibers surface loaded ZnO particles as a potential biodegradable antibacterial wound dressing. Nanomaterials 2019, 9, 525. [CrossRef] [PubMed]

35. Mamun, A. Review of possible applications of nanofibrous mats for wound dressings. Tekstilec 2019, 62, 89-100. [CrossRef] 
36. Wehlage, D.; Blattner, H.; Sabantina, L.; Böttjer, R.; Grothe, T.; Rattenholl, A.; Gudermann, F.; Lütkemeyer, D.; Ehrmann, A. Sterilization of PAN/gelatine nanofibrous mats for cell growth. Tekstilec 2019, 62, 78-88. [CrossRef]

37. Wehlage, D.; Böttjer, R.; Grothe, T.; Ehrmann, A. Electrospinning water-soluble/insoluble polymer blends. AIMS Mater. Sci. 2018, 5, 190-200. [CrossRef]

38. Sabantina, L.; Böttjer, R.; Wehlage, D.; Grothe, T.; Klöcker, M.; García-Mateos, F.J.; Rodríguez-Mirasol, J.; Cordero, T.; Ehrmann, A. Morphological study of stabilization and carbonization of polyacrylonitrile/TiO 2 nanofiber mats. J. Eng. Fibers Fabr. 2019, 14. [CrossRef]

39. Grothe, T.; Böttjer, R.; Wehlage, D.; Großerhode, C.; Storck, J.L.; Juhász Junger, I.; Mahltig, B.; Grethe, T.; Graßmann, C.; Schwarz-Pfeiffer, A.; et al. Photocatalytic properties of $\mathrm{TiO}_{2}$ composite nanofibers electrospun with different polymers. In Inorganic and Composite Fibers; Mahltig, B., Kyosev, Y., Eds.; Woodhead Publishing: Cambridge, UK, 2018; pp. 303-319.

40. Dentani, T.; Kubota, Y.; Funabiki, K.; Jin, J.; Yoshida, T.; Minoura, H.; Miura, H.; Matsui, M. Novel thiopene-confugated indoline dyes for zinc oxide solar cells. New J. Chem. 2009, 33, 93-101. [CrossRef]

41. Salih, E.Y.; Sabri, M.F.M.; Tan, S.T.; Sulaiman, K.; Hussein, M.Z.; Said, S.M.; Yap, C.C. Preparation and characterization of $\mathrm{ZnO} / \mathrm{ZnAl}_{2} \mathrm{O}_{4}$-mixed metal oxides for dye-sensitized photodetector using $\mathrm{Zn} /$ Al-layered double hydroxide as precursor. J. Nanoparticle Res. 2019, 21, 55. [CrossRef]

42. Saboor, A.; Shah, S.M.; Hussain, H. Band gap tuning and applications of ZnO nanorods in hybrid solar cell: Ag-doped verses Nd-doped ZnO nanorods. Mater. Sci. Semicond. Process. 2019, 93, 215-225. [CrossRef]

43. Sehgal, P.; Narula, A.K. Metal substituted metalloporphyrins as efficient photosensitizers for enhanced solar energy conversion. J. Photochem. Photobiol. A Chem. 2019, 375, 91-99. [CrossRef]

44. Mamun, A.; Trabelsi, M.; Klöcker, M.; Sabantina, L.; Großerhode, C.; Blachowicz, T.; Grötsch, G.; Cornelißen, C.; Streitenberg, A.; Ehrmann, A. Electrospun nanofiber mats with embedded non-sintered $\mathrm{TiO}_{2}$ for dye sensitized solar cells (DSSCs). Fibers 2019, 7, 60. [CrossRef]

45. Becheri, A.; Dürr, M.; Lo Nostro, P.; Baglioni, P. Synthesis and characterization of zinc oxide nanoparticles: Application to textiles as UV-absorbers. J. Nanoparticle Res. 2008, 10, 679-689. [CrossRef]

46. Xiong, G.; Pal, U.; Serrano, J.G.; Ucer, K.B.; Williams, R.T. Photoluminescence and FTIR study of ZnO nanoparticles: The impurity and defect perspective. Phys. Status Solidi 2006, 10, 3577-3581. [CrossRef]

47. Mamun, A.; Trabelsi, M.; Wortmann, M.; Frese, N.; Moritzer, E.; Gölzhäuser, A.; Hüsgen, B.; Sabantina, L. Stabilization and carbonization of PAN/PVDF nanofiber blend scaffolds. In preparation. 